\title{
Set-up and pilot of a population cohort for the study of the natural history of COPD and OSA: the PULSAIB study
}

\author{
*Joan B Sorianoa, Aina Yáñeza, Feliu Renom, Mónica de la Peñac, Amalia Gómez , \\ Rosa Duroe, Ana Uréndez', Miguel Román ${ }^{f}$
}

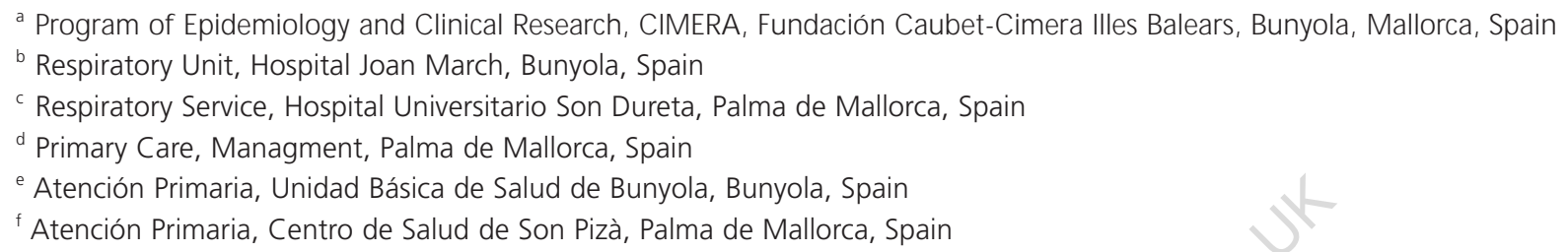

Received 18th September 2009; revised 2nd December 2009; accepted 19th December 2009; online 18th February 2010

\begin{abstract}
Aims: We describe the set-up of a population-based study focussed on respiratory conditions, and describe a pilot study - the PULmons SAns Illes Balears (PULSAIB) study - aimed at investigating the natural history of COPD, obstructive sleep apnoea (OSA), and other common chronic diseases.

Methods: A cross-sectional study was designed to survey two fieldwork areas, one rural and one urban, in the Balearic Islands, Spain. Tests conducted included a questionnaire, spirometry with post-bronchodilator (PBD) test, and portable respiratory polygraphy.

Results: We assessed all processes and tools to be used, and piloted them in 175 participants from Bunyola (rural) and 130 participants from the Son Pizà area (urban). Within this first cross-sectional assessment of the Balearic population aged 30 to 80 years, we report the prevalence of airflow limitation defined as a PBD FEV $1 / F V C$ ratio $<0.7$ and the prevalence of OSA defined as an apnoea-hypopnoea index $(\mathrm{AHI})>10 /$ hour.

Conclusion: A cohort study in the Balearic population to investigate the natural history of COPD and OSA is feasible.

(C) 2010 Primary Care Respiratory Society UK. All rights reserved.

J Soriano et al. Prim Care Resp J 2010; 19(2): 140-147

doi:10.4104/pcrj.2010.00010
\end{abstract}

Keywords COPD, co-morbidities, general population, natural history, OSA, primary care

\section{Introduction}

Respiratory diseases represent an important disease burden worldwide, both in absolute and relative terms. Chronic obstructive pulmonary disease (COPD) and obstructive sleep apnoea (OSA) produce frequent morbidity and mortality in adults, yet the causes of their apparent increased prevalence in the population and the factors related with their incidence in individual cases, remain incompletely understood. There are no known respiratory-focussed population studies describing the natural history, frequency of occurrence and distribution of COPD and OSA, in the Balearic Islands, Spain.
In Europe, respiratory diseases rank second (after cardiovascular diseases) in terms of mortality, incidence, prevalence and costs, ${ }^{1}$ but there is considerable variation. The reasons for these variations are not clear and have been highlighted as an area of future research.

The 1990 global estimates of mortality per disease have been updated recently. They confirm that COPD - which was the fifth commonest cause of death in 1990 - has been the fourth commonest cause since 2000 and will become the third commonest killer by $2020 .^{2}$ In Spain, the IBERPOC study, a landmark prevalence survey conducted in 1997, ${ }^{3}$ reported

\footnotetext{
* Corresponding author: Dr Joan B Soriano, Fundación Caubet-Cimera Illes Balears, Program of Epidemiology and Clinical Research, CIMERA Bunyola, Mallorca 07110, Spain. Tel: +34 971148437 Fax: +34 971148442 E-mail: jbsoriano@caubet-cimera.es
} 
that $9.1 \%$ of the general Spanish population aged between 40 and 69 years had COPD, with a wide range in the seven areas studied from $4.9 \%$ to $18.0 \%$. These estimates have been updated recently with the EPI-SCAN study, a new survey conducted in 2008, which reported a COPD prevalence of $10.2 \%$ in individuals aged 40 to 80 years using current spirometry definitions. ${ }^{4}$

There is scarce data on the population distribution of OSA. Limited data on sleep-related conditions are available for some Western European countries, and show wide variation. ${ }^{1}$ Although not often acknowledged as a worldwide problem, OSA affects $2-4 \%$ of middle-aged men and $1-2 \%$ of middleaged women, whilst the majority of affected individuals remain undiagnosed. ${ }^{5}$ On the basis of average prevalence estimates from various studies of predominantly white men and women with a mean body mass index (BMI) of 25 to 28, Young et al. ${ }^{6}$ estimated that roughly one in five adults has at least mild OSA and one in 15 at least moderate OSA. In Spain, the population prevalence of OSA was estimated among a sample of 1,360 Spanish adults, where $0.8 \%$ of women and $2.2 \%$ of men met the diagnostic criteria for clinical OSA. ${ }^{7}$ However, Duran et al. ${ }^{8}$ found the prevalence of an apnoeahypopnoea index $(\mathrm{AHI})>10 /$ hour to be $19 \%$ in men and $15 \%$ in women from a population sample aged 30 to 70 years in Vizcaya (Spain). The interrelationship between COPD and OSA has not yet been completely determined, although an increase in OSA-related symptoms in COPD patients, in contrast to asthma patients, identifies the former as a target group for the screening of OSA in primary care. ${ }^{9}$

The natural history of any given disease refers to a description of the uninterrupted progression of the disease in an individual, from the moment of exposure to causal agents, until recovery or death. ${ }^{10}$ Knowledge of the natural history of disease is considered fundamental for the causal understanding of mechanisms and the control of disease. However, in contrast to cardiovascular disease or cancer, there are no population studies describing most respiratory conditions. Indeed, one of the first priorities for future respiratory research identified by a panel of experts from the British Thoracic Society was "... to better study the natural history of early development of the respiratory tract and immune system and the techniques needed to understand normal air growth, development and decline in health and disease". ${ }^{11}$ On the one hand, the currently established model on the natural history of COPD - characterised by an accelerated decline of lung function that occurs with ageing and is enhanced by smoking - was established more than 30 years ago, ${ }^{12}$ but was not validated in full (as described elsewhere, ${ }^{13,14}$ ) until recently. ${ }^{15}$ On the other hand, the study of the natural history of OSA has been hindered by problems with definitions and other limitations. ${ }^{16}$
We therefore established a multidisciplinary group to setup a population cohort in the Balearic Islands, Spain, to investigate the natural history of COPD, OSA, and other common chronic conditions. The group includes primary care doctors, pneumologists, epidemiologists, and others. The final aim and primary objective of this research is to establish and co-ordinate a population cohort study aimed to investigate the natural history of the most common respiratory chronic conditions, including COPD and OSA. Such a population cohort should evolve as a research framework with a hub of researchers, as has occurred with other studies such as Framingham, ${ }^{17,18}$ Rotterdam, $^{19}$ Vlagtwedde-Vlaardingen, ${ }^{20}$ OLIN, ${ }^{21}$ Copenhagen ${ }^{22}$ and others, as reviewed elsewhere. ${ }^{23,24}$

\section{Methods}

The design of this study is a first cross-sectional assessment, eventually to be followed up in time and expanded in size to set up a prospective cohort study. All participants gave informed written consent and the research protocol was approved by our Ethics Review Board [www.ceicsalut.com/ pag-cat/index.html coded No IB 767/07].

\section{Sample size}

Considering a prevalence of COPD of $10 \%$ and a participation of at least $70 \%$, to obtain an estimate of the prevalence with an accuracy of $\pm 3 \%$, it was estimated (with an alpha error of $5 \%$ and a beta error of $20 \%$ ) that a sample size of 500 subjects per area was deemed necessary to obtain a response from 350 participants.

\section{Sampling and fieldwork}

The sample was obtained from the population domain of the Primary Care Centres of a rural setting (Bunyola), as well as an urban setting (Son Pizà, Palma de Mallorca) (Figure 1). We randomly selected an age- and gender-stratified sample of

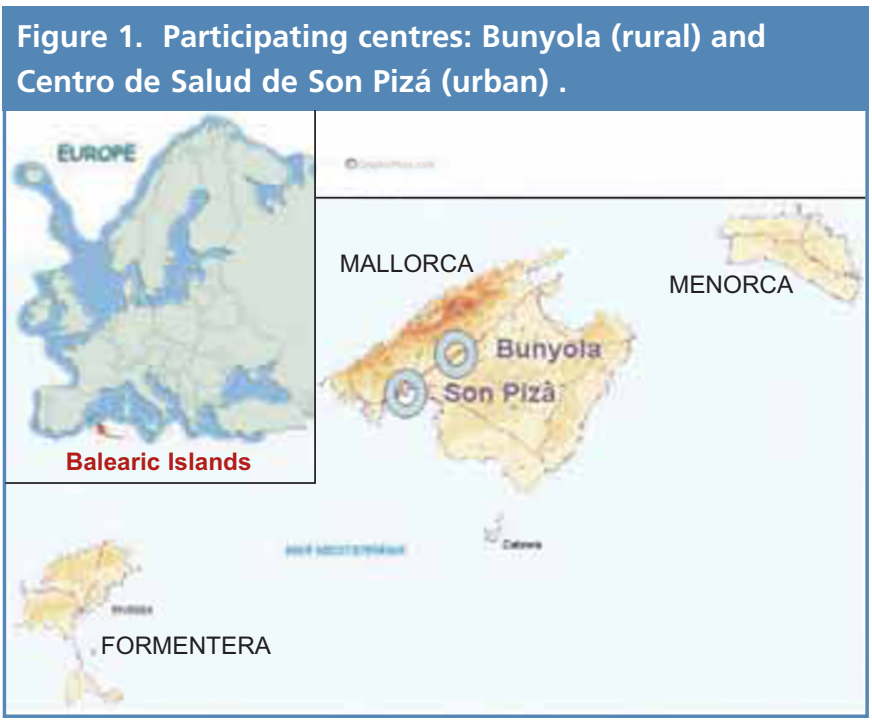


JB Soriano et al.

500 individuals from each Primary Care Centre. The inclusion criteria in this study were: age 30 to 80 years; being resident in Mallorca in the catchment area of the Primary Care Centres with a corresponding Health Card; and willingness to participate in the study and to sign informed consent. Exclusion criteria were: very serious illness (terminal or serious physical/mental disability) that might prevent monitoring and participation in the study; and inability to sign the informed consent. Similarly, we excluded those individuals with communication or comprehension difficulties.

Description of the questionnaires for data collection A questionnaire for data collection was developed at cohort inception; this included assessment of sociodemographic data, weight and height, smoking history, consumption of alcohol, previous diagnosis of COPD or OSA, presence of COmorbidities, personal and family history of disease, and history of other toxic habits or drug use. Diurnal somnolence was assessed by the Epworth test. ${ }^{25}$ All participants in the study were assigned a unique identifier that was used for coding in the questionnaire and in each of the tests. The tests were: forced spirometry pre- and post-bronchodilator conducted according to current international guidelines ${ }^{26}$ by means of portable spirometers (Easy One NDDTM, Medical Technologies, Zurich, Switzerland); home respiratory polygraphy by means of portable devices (ApneaLinkTM, ResMed Corporation, Poway, California, USA); and extraction of $30 \mathrm{ml}$ of venous blood.
Figure 2. CONSORT flowchart of participation in Bunyola (rural) and Centro de Salud de Son Pizá (urban).

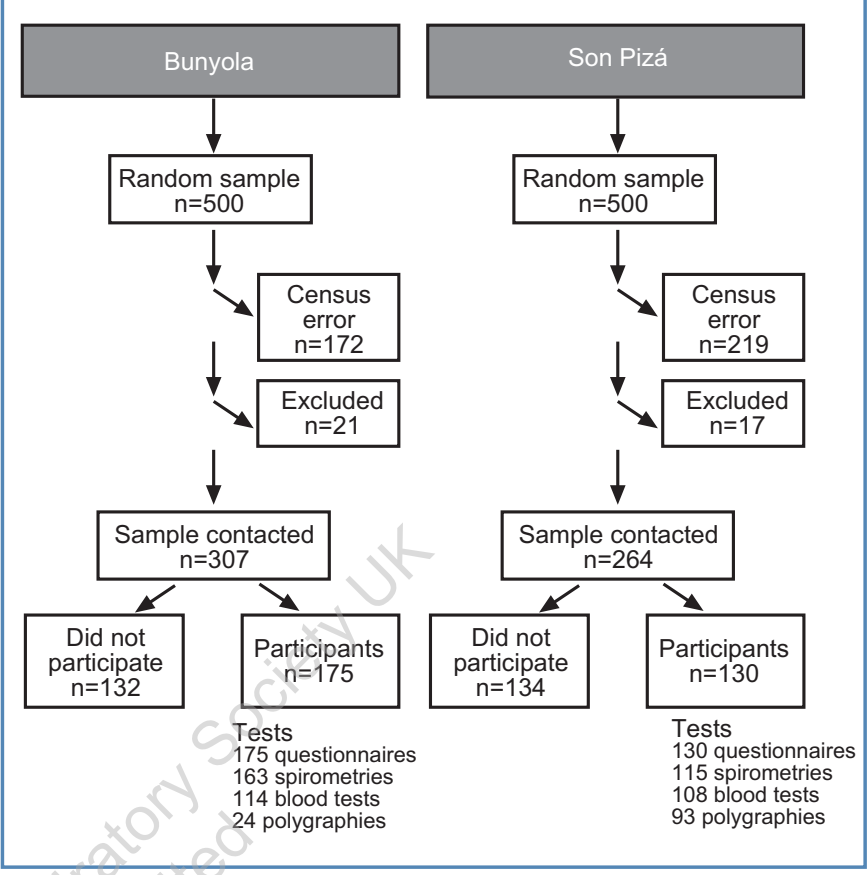

\section{Analysis}

The primary study variables were presence of airflow limitation compatible with COPD as defined according to the Global Initiative for Obstructive Lung Disease (GOLD)

Table 1. Baseline sociodemographic characterististics: per centre and total.

\begin{tabular}{|c|c|c|c|}
\hline & Son Pizá & Bunyola & Total \\
\hline $\mathrm{N}$ & 130 & 175 & 305 \\
\hline Age, mean $\pm S D$ & $57.1 \pm 13.7$ & $55.7 \pm 13.3$ & $56.3 \pm 13.5$ \\
\hline Female, $n(\%)$ & $62(47.7)$ & $88(50.3)$ & $150(49.2)$ \\
\hline $\begin{array}{l}\text { Living status, } \mathrm{n}(\%) \\
\text { Couple } \\
\text { With children } \\
\text { With parents }\end{array}$ & $\begin{array}{c}105(80.8) \\
51(39.3) \\
5(3.8) \\
\end{array}$ & $\begin{array}{c}131(74.9) \\
88(50.3) \\
7(4.0) \\
\end{array}$ & $\begin{array}{l}236(77.4) \\
139(45.6) \\
12(3.9) \\
\end{array}$ \\
\hline $\begin{array}{l}\text { Working status, } \mathrm{n}(\%) \\
\text { Active worker } \\
\text { Unemployed } \\
\text { Retired } \\
\text { Housekeeper } \\
\text { Other }\end{array}$ & $\begin{array}{c}57(44.9) \\
4(3.2) \\
54(42.5) \\
9(7.1) \\
3(2.4) \\
\end{array}$ & $\begin{array}{c}82(47.9) \\
2(1.2) \\
57(33.3) \\
24(14) \\
6(3.5)\end{array}$ & $\begin{array}{c}139(46.6) \\
6(2.0) \\
111(37.2) \\
33(11.1) \\
9(3.1)\end{array}$ \\
\hline Weight, mean \pm SD & $73.0 \pm 14.7$ & $76.1 \pm 14.1$ & $74.8 \pm 14.5$ \\
\hline Height, mean \pm SD & $162,4 \pm 8,9$ & $165,6 \pm 9,0$ & $164,3 \pm 9,1$ \\
\hline $\begin{array}{l}\text { BMI, mean } \pm \text { SD } \\
\text { Overweight, } \mathrm{n}(\%) \\
\text { Obesity, } \mathrm{n}(\%)\end{array}$ & $\begin{array}{l}27,5 \pm 4,5 \\
48(37,2) \\
39(30.2)\end{array}$ & $\begin{array}{l}27.6 \pm 4.2 \\
73(41.7) \\
51(29.1)\end{array}$ & $\begin{array}{c}27.6 \pm 4.3 \\
121(39.8) \\
90(29.6)\end{array}$ \\
\hline Abdominal perim., mean \pm SD & $92.8 \pm 13.8$ & $94.7 \pm 13.1$ & $93.9 \pm 13.4$ \\
\hline Abdominal perim. of risk. $\mathrm{n}(\%)$ & $59(45.4)$ & $93(53.1)$ & $152(49.8)$ \\
\hline $\begin{array}{l}\text { Smoking, } \mathrm{n}(\%) \\
\text { Current- } \\
\text { Former- } \\
\text { Never- }\end{array}$ & $\begin{array}{l}37(28.9) \\
49(38.3) \\
42(32.8)\end{array}$ & $\begin{array}{l}40(23.8) \\
44(26.2) \\
84(50.0)\end{array}$ & $\begin{array}{c}77(26.0) \\
93(31.4) \\
126(42.6)\end{array}$ \\
\hline
\end{tabular}

$\mathrm{BMI}=$ body mass index 
guidelines by a post-bronchodilator forced expiratory volume in one second $\left(\mathrm{FEV}_{1}\right) /$ forced vital capacity $(\mathrm{FVC})$ ratio $<0.70,27$ and OSA as defined by an AHI >10/hour. Data was keyed in periodically, and accuracy and quality was double-checked. Data cleaning was conducted by means of tests of ranks (to detect any possible, extreme, outlier, and error values), and crossings of logical fields to detect inconsistencies between responses. The prevalence of COPD and OSA, with their $95 \%$ confidence intervals was calculated, in the totality of the sample, by centre, gender and ages. Comparative analyses were made with independent variables by study groups with T-test and $\mathrm{Chi}^{2}$, wherever appropriate. A $\mathrm{p}$ value lower than 0.05 was considered statistically significant.

\section{Results}

Within this pilot, cross-sectional assessment, the total number of participants was 305; 130 in Son Bunyola and 175 in Son Pizà (Figure 2). A non-response study indicated that the age and gender distribution of non-participants was as follows: $47 \%$ women, with a mean age of 54.7 years; and by centre, in Son Pizà 50\% female and age 54.2 years, while in Bunyola $46 \%$ female and age 54.9 years. There were no significant differences between participants and non participants regarding their age and sex distribution ( $p>0.05$ ).

The socio-demographic characteristics of participants are presented in Table 1. Mean age was 56 years and $49 \%$ were women. Most participants (77\%) lived with a partner and the more frequent employment status was working $(46.6 \%)$ or retired $(37.2 \%)$. There was a substantial prevalence of overweight (40\%) and obesity (29.6\%), with $50 \%$ having an abdominal perimeter putting them at risk. Regarding smoking history; $27.5 \%$ of men and $19 \%$ of women were regular smokers (combined $23 \%$ ), 3\% were occasional smokers, $31 \%$ former-smokers and $43 \%$ never-smokers. The average packyears smoked was $25.9 \pm 19.9$ and the number of cigarettes smoked per day $15.8 \pm 8.8$ (data not shown). There were no differences in any variables between the Son Pizà versus the Bunyola participants

The most common self-reported co-morbidity was osteoarthritis $(33 \%)$, although in Bunyola it was anxiety/depression (Table 2). Four out of five respondents reported having one or more co-morbidities. The prevalence of hypertension (53.8\%), hyperlipidaemia (29\%), and diabetes $(16 \%)$ were slightly higher than current epidemiological data reported from the Balearics. The underdiagnosis of hyperlipidaemia and diabetes was less than $20 \%$, while only

Table 2. Co-morbidity distribution: per centre and total.

\begin{tabular}{|c|c|c|c|}
\hline & Son Pizá & Bunyola & Total \\
\hline Myocardial infarction & $5(3.9)$ & $3(1.7)$ & $8(2.7)$ \\
\hline Other heart problems & $14(11.0)$ & $18(10.3)$ & $32(10.6)$ \\
\hline Peripheral vascular disease & $3(2.4)$ & $4(2.3)$ & $7(2.3)$ \\
\hline Cerebrovascular disease & $5(3.9)$ & $1(0.6)$ & $6(2.0)$ \\
\hline Anxiety, depression & $27(21.3)$ & $65(37.6)$ & $92(30.7)$ \\
\hline Arthritis, osteoarthritis & $42(32.8)$ & $58(33.3)$ & $100(33.1)$ \\
\hline Osteoporosis & $11(8.6)$ & $20(11.5)$ & $31(10.3)$ \\
\hline Acid peptic disease & $15(11.7)$ & $19(10.9)$ & $34(11.3)$ \\
\hline Chronic hepatitis, cirrhosis & $8(6.3)$ & $11(6.4)$ & $19(6.4)$ \\
\hline Thyroid Disease & $9(7.0)$ & $9(5.2)$ & $18(6.0)$ \\
\hline Glaucoma & $5(3.9)$ & $12(6.9)$ & $17(5.6)$ \\
\hline Cataracts & $23(18.1)$ & $27(15.6)$ & $50(16.7)$ \\
\hline Severe kidney disease & $2(1.6)$ & $2(1.1)$ & $4(1.3)$ \\
\hline Irritable bowel & $11(8.7)$ & $15(8.6)$ & $26(8.6)$ \\
\hline Cancer & $4(3.1)$ & $6(3.5)$ & $10(3.3)$ \\
\hline Chronic infections & $1(0.8)$ & 0 & $1(0.3)$ \\
\hline Neurological diseases & $1(0.8)$ & $1(0.6)$ & $2(0.7)$ \\
\hline Participants with 1 or more conditions & $90(85.7)$ & $131(78.9)$ & $221(81.5)$ \\
\hline High blood pressure, n (\%) & $68(52.3)$ & $96(54.9)$ & $164(53.8)$ \\
\hline HBP diagnosed/total, a/n (\%) & $40 / 68(58.8)$ & $49 / 96(51)$ & $89 / 162(54.9)$ \\
\hline HBP controlled/uncontrolled, b/c (\%) & $10 / 40(25)$ & $17 / 49(34.6)$ & $27 / 89(30.3)$ \\
\hline Diabetes, $\mathrm{n}(\%)$ & $15 / 105(14.3)$ & 24/142 (16.9) & $39 / 247(15.8)$ \\
\hline Diabetes diagnosed/total, a/n (\%) & $13 / 15(86.7)$ & 20/24 (83.3) & $33 / 39(84.6)$ \\
\hline Diabetes controlled/uncontrolled, b/c (\%) & $9 / 13(69.2)$ & $8 / 20(40)$ & $17 / 33(51.5)$ \\
\hline Hyperlipidaemia, n (\%) & $28 / 107(26.2)$ & $42 / 137(30.7)$ & $70 / 244(28.7)$ \\
\hline Hyperlipid. diagnosed/total, a/n (\%) & $24 / 28(85.7)$ & 35/42 (83.3) & $59 / 70(84.3)$ \\
\hline Hyperlipid. controlled/uncontrolled, b/c (\%) & $19 / 24(79.2)$ & 25/35 (71.4) & $44 / 59(74.6)$ \\
\hline
\end{tabular}


JB Soriano et al.

\begin{tabular}{|c|c|c|c|}
\hline & Son Pizá & Bunyola & Total \\
\hline $\mathrm{FEV}_{1}$ in litres, mean $\pm \mathrm{SD}$ & $2.6(0.7)$ & $2.8(0.8)$ & $2.7(0.8)$ \\
\hline $\mathrm{FEV}_{1}$ percent predicted, mean $\pm \mathrm{SD}$ & $86.1(15.2)$ & $89.7(16.9)$ & $88.0(16.2)$ \\
\hline FVC in litres, mean $\pm S D$ & $3.3(0.9)$ & $3.5(0.9)$ & $3.4(0.9)$ \\
\hline FVC percent predicted, mean \pm SD & $85.0(13.8)$ & $86.6(14.5)$ & $85.9(14.2)$ \\
\hline $\mathrm{FEV}_{1} / \mathrm{FVC}$, mean $\pm \mathrm{SD}$ & $0.8(0.1)$ & $0.8(0.1)$ & $0.8(0.1)$ \\
\hline COPD, n (\%) & $12(12.5)$ & $14(13.1)$ & $26(12.8)$ \\
\hline \multicolumn{4}{|l|}{ GOLD-stage severity, n (\%) } \\
\hline Mild & $2(2.1)$ & $5(4.7)$ & $7(3.4)$ \\
\hline Moderate & $8(8.3)$ & $7(6.5)$ & $15(7.4)$ \\
\hline Severe & $2(2.1)$ & $2(1.9)$ & $4(2.0)$ \\
\hline COPD in male participants, $\mathrm{n}(\%)$ & $11(21.2)$ & $10(17.5)$ & $21(19.6)$ \\
\hline COPD in female participants, $\mathrm{n}(\%)$ & $0(0)$ & $5(9.6)$ & $5(5.2)$ \\
\hline
\end{tabular}

$55 \%$ of participants with hypertension were diagnosed, and of these only $30 \%$ were well controlled (Table 2 ).

A total of 300 spirometry readings were obtained, of which $203(67.3 \%)$ passed the ATS/ERS quality control standards (Table 3), 94 in Son Pizà and 109 in Bunyola. According to the GOLD criteria (PBD FEV $1 /$ FVC ratio <0.7), 12.8\% (95\% Cl 8.518.2) of participants had irreversible airway obstruction consistent with COPD - by gender, $20 \%$ in men and $5 \%$ in women - and the distribution of COPD severity was $27 \%$ mild, $58 \%$ moderate, and $15 \%$ severe. By centre, the prevalence of airway limitation compatible with COPD was $12.5 \%$ in Son Pizà and $13.1 \%$ in Bunyola. The bronchodilator test, defined in this pilot study as an increase in $\mathrm{FEV}_{1}$ repeated 15 minutes after inhalation of $200 \mathrm{mcg}$ of salbutamol greater than $12 \%$ of baseline and greater than $200 \mathrm{ml}$ in absolute terms, was positive in $26.9 \%$ of the participants who met the criterion of COPD, and in only $5.1 \%$ of the other participants $(p<0.001)$.

According to the Epworth scale, there were $70.8 \%$ normal individuals, $18.7 \%$ with mild diurnal somnolence, $6.6 \%$ with moderate somnolence, and 3.9\% with severe somnolence, with no difference between the centres. A total of 117 home respiratory polygraphies were conducted, 93 in Son Pizà and 24 in Bunyola (Table 3). Of these, a total of 78 (67\%) were considered valid after quality control. In men, 39.4\% of polygraphs were not valid, this percentage being lower in females (23.9\%). From all valid tests, the obtained prevalence of OSA defined as an AHI >10/hour was 35.9\% (95\% CI 25.347.6). The percentage of patients with OSA by gender was $42 \%$ in men and $29 \%$ in women (Table 4). Two participants reported a previous diagnosis of OSA.

\section{Discussion}

Obstructive respiratory disease in general, and COPD in particular, have a tremendous impact on patients, healthcare systems and society. OSA also carries a significant individual burden, and is identified as an independent risk factor for cardiovascular disease and a main contributor to road traffic accidents. The natural history of COPD and OSA can be life threatening, and includes changes in symptoms, quality of life and utilisation of healthcare resources, as well as changes in the function or pathology of the lungs.

Only a few studies have aimed to investigate the natural history of COPD, with only partial results, and there are virtually no studies on OSA. Although an increasing amount of information about lung function growth is being gathered, many unknowns remain about lung function decline. Perhaps the "perfect" COPD and OSA longitudinal study should involve a comprehensive clinical history combined with periodical lung function assessment, repeated respiratory polygraphy, biomarkers, imaging, and/or direct exposure

Table 4. Sleep polygraphy results: per centre and total.

\begin{tabular}{|c|c|c|c|}
\hline OSA according to AHI, $\mathrm{n}(\%)$ & Son Pizá & Bunyola & Total \\
\hline Normal & $38(40.9)$ & $12(50.0)$ & $50(42.7)$ \\
\hline Mild & $8(8.6)$ & $3(12.5)$ & $11(9.4)$ \\
\hline Moderate & $4(4.3)$ & $2(8.3)$ & $6(5.1)$ \\
\hline Severe & $4(4.3)$ & $2(8.3)$ & $6(5.1)$ \\
\hline Very severe & $4(4.3)$ & $1(4.2)$ & $5(4.3)$ \\
\hline Not valid & $35(37.6)$ & $4(16.7)$ & $39(33.3)$ \\
\hline $\mathrm{AHI}>10$ in male participants, $\mathrm{n}(\%)$ & $12(48.0)$ & $6(38.0)$ & $(41.9)$ \\
\hline $\mathrm{AHI}>10$ in female participants, $\mathrm{n}(\%)$ & $8(25.0)$ & $2(66.7)$ & $(28.6)$ \\
\hline
\end{tabular}


measures. This would enable one to study comprehensively the changes in lung function in various age groups, from decreased lung function growth in teenagers to accelerated decline in lung function in smokers and others. In this context it is our primary aim to determine the relationship between lung function decline and gender and environmental exposures (both smoking and non-smoking related factors), to gather important information regarding the prognosis of COPD, and therefore to help improve developing strategies aimed at early detection and treatment of the causes of exacerbations and the development of sequelae. Similarly, a population study on the natural history of OSA would help to quantify incidence and trigger factors, and expand our knowledge on the long-term consequences of snoring, somnolence, and other symptoms.

Previous COPD and OSA research likely suffers from the so-called "iceberg phenomenon", a metaphor emphasising that for virtually every health problem the number of known cases of disease is outweighed by those that remain undiscovered. Both conditions are associated with significant underdiagnosis (80\% in COPD and up to $90 \%$ in OSAS), and accordingly with undertreatment. ${ }^{28}$ The iceberg phenomenon often thwarts attempts to assess the burden of disease and the need for services, as well as the selection of representative cases for study. This leads to what has been called the "clinician's fallacy", in which an inaccurate view of the nature and causes of a disease results from studying the minority of cases of the disease that are seen in clinical treatment settings..$^{29,30}$ Only a population approach, like the one suggested in the current future cohort proposal, can overcome the "clinician's fallacy" of our current knowledge of the natural history of COPD and OSA.

\section{Limitations of this study}

These are listed and briefly discussed below, with the aim being to correct and/or implement these factors in the cohort study extension, and also to help other researchers considering similar studies.

\section{- Sample selection}

The use of the Health Card data raised confidentiality issues in the central headquarters of the issuing entity (IBSalut), which slowed the selection of participants. The available mailing addresses and phone information were of poor quality and not up to date, so extensive lists of substitutes were used, which in turn created problems in the randomisation and generalisation. The vast majority of exclusions were due to census errors (39\%), and fieldwork to update addresses and phone numbers was tedious and inefficient. We propose to study further the use of more reliable population census updates as well as the Municipal records. One possible limiting factor we considered a priori was participation bias by differing age and gender. However, our non-response analysis indicated that these factors had a reduced influence, and the sample obtained was representative of the study population, with a distribution similar to the original reference population by age and gender.

Of the 350 participants initially estimated, 305 were finally studied; 175 in Bunyola and 130 in Son Pizà. It was decided to close the study with this number of participants - having exhausted the initial list of 1,000 patients - due to the methodological difficulties in selecting a new sample.

The recruitment of participants was performed via an introductory letter and subsequent telephone contact. We detected a high percentage of the population that refused to participate in the study (47\%). To reduce this non-response, improved communication with selected candidates using more encouraging language or the media could be considered.

\section{- Information for participants}

The invitation letter to participants, information material, and informed consent form were considered appropriate. However, subsequent information on test results and thankyou letters were controversial within researchers in this group.

\section{- Staff and location}

We highlight the professionalism, but also the enthusiasm and volunteerism, of all those involved in the fieldwork. The use of temporary staff (registered nurses and nursing students) for fieldwork worked unevenly. Undertaking fieldwork in variable days and hours were difficult. For further studies it would be desirable to have permanent staff, fulltime or with availability in a wider time slot, as well as a unique location suitable for carrying out the questionnaires and tests in each health centre.

\section{- Database and document repository}

The difficulty of keeping the database of results and their corresponding regular backups were an unanticipated limitation. In particular, data should be linked with spirometric results bi-weekly or monthly, and the validity of the quality of curves and other data evaluated periodically.

\section{- Spirometry}

The use of portable spirometers was acceptable. Their handling was simple and they were considered low maintenance. However, the choice of reference values in the menu and the clicking of participants' information were difficult, and absence of a real-time display of spirometric curves (which has recently been recommended ${ }^{31}$ ) may have generated a higher number of invalid spirometry readings. Fieldworkers passed a quality control test, but the yield of valid spirometry readings (67.3\%) was medium to low compared to that found in similar studies. One of the eight fieldworkers was identified as having a serious quality control problem, producing a high number of invalid spirometric tests $(>50 \%)$. The quality control was carried out at the end of 
fieldwork, which prevented an appropriate correction during study development. This stresses the importance of a detailed assessment and continuous quality control of data and staff on a monthly basis.

\section{- Home respiratory polygraphy}

At study start, there were only two polygraphs that had to be rotated, so they were only offered to a minority of participants $(38 \%)$ at the criteria of the fieldworker. This might have created a bias to select individuals with an a priori higher risk of OSA, and likely inflated the obtained prevalence rate. A higher than expected number of respiratory polygraphs was considered not valid $(33 \%)$, particularly in males (39.4\%). To minimise this problem a leaflet was created explicitly giving further instructions, and graphically displaying the correct placement of the home polygraph. Indeed, due to the logistical sampling problems stated above, and by discarding one in three measuremements after quality control, the representative nature of our participants is reduced, and this might be partly responsible for our high point estimates of OSA in male and female participants (both with wide confidence intervals around). However, as reviewed by Young et al., ${ }^{6}$ three larger population-based studies using the same definition of OSA (AHI index $\geq 10$ ) like us, reported OSA in percentages up to $26 \%$, all greater than the previously-considered 'normal' OSA prevalence of 2 to $4 \%$. Therefore, by expanding our cohort we might confirm that in the Balearic Islands the prevalence of OSA is in the highend of the population OSA prevalence. Of interest, the distribution of somnolence by the Epworth scale was not consistent by OSA severity (data not shown), but the percentage of those who passed/did not pass the polygraphy quality control was identical (one in three) according to the Epworth score severity of diurnal somnolence.

\section{- Institutional support}

Three factors are considered essential to the success of any population-based study of natural history, ${ }^{13}$ namely infrastructure, collaboration, and institutional support. In terms of infrastructure, the present and future availability of testing rooms to perform these studies is essential; collaboration develops by close co-operation and volunteerism amongst the research group and participants, as well as the professionalism of fieldworkers; and it is essential to maintain and increase home institutional support and support from funding agencies.

\section{Condusion}

Although the aim of this pilot study was not to conduct a prevalence study per se, these results indicate that both COPD and OSA are common diseases in the Balearic population aged 30 years and older. We conclude that it is viable and feasible to perform a cohort study in the Balearic population aimed at investigating the natural history of the two most common chronic respiratory diseases, COPD and OSA.

\section{Conflict of interest declarations}

We declare there are no conflicts of interest related with the research presented.

\section{Acknowledgements}

The PULSAIB study was funded by a grant of December 22, 2006 to establish Grup Emergent de Recerca from the Direcció General de Recerca, Desenvolupament i Tecnològic Innovació, Conselleria d'Economia, Hisenda i Innovació del Govern de les Illes Balears. The PULSAIB study has received the endorsement of the Spanish Society of Pneumology and Thoracic Surgery-SEPAR [http://www.separ.es] within the PII de EPOC. Carburos Metálicos kindly lent four portable polygraphs for this study. We thank fieldworkers (Eva Rodríguez, Rebeca Yeguas, Nieves Perea, Paco Noriega, Lillian Mota and Raquel Verd) for their dedication and enthusiasm. We are also grateful to the managers and coordinators of the Health Centers of Son Pizà and Unitat Bàsica de Bunyola to use their facilities. Finally, we have to sincerely thank the participants, without their generous, selfless collaboration this study could not be undertaken. These results were presented in abstract form in the 2009 European Respiratory Society Annual Congress in Vienna, Austria.

\section{References}

1. The European Lung White Book: The First Comprehensive Survey on Respiratory Health in Europe. ERS 2004.

2. Lopez $A D$, Shibuya $K$, Rao $C$, et al. Chronic obstructive pulmonary disease: current burden and future projections. Eur Respir J 2006;27:397-412. http://dx.doi.org/10.1183/09031936.06.00025805

3. Sobradillo-Peña V, Miravitlles M, Gabriel R, et al. Geographical variations in prevalence and underdiagnosis of COPD. Results of the IBERPOC multicentre epidemiological study. Chest 2000;118:981-9. http://dx.doi.org/ 10.1378/chest.118.4.981

4. Miravitlles M, Soriano JB, Garcia-Rio R, et al. Prevalence of COPD in Spain: impact of undiagnosed COPD on quality of life and daily life activities. Thorax 2009;64:863-8. http://dx.doi.org/10.1136/thx.2009.115725).

5. Gibson GJ. Obstructive sleep apnoea syndrome: underestimated and undertreated. Br Med Bull 2005;72:49-65. http://dx.doi.org/ 10.1093/bmb/ldh044

6. Young T, Peppard PE, Gottlieb DJ. Epidemiology of Obstructive Sleep Apnea. A Population Health Perspective. Am J Respir Crit Care Med 2002;165:1217-39. http://dx.doi.org/10.1164/rccm.2109080.

7. Marin JM, Gascon JM, Carrizo S, Gispert J. Prevalence of sleep apnoea syndrome in the Spanish adult population. Int J Epidemiol 1997;26:381-6. http://dx.doi.org/10.1093/ije/26.2.381

8. Duran J, Esnaola S, Rubio R, Iztueta A. Obstructive Sleep Apnea-Hypopnea and Related Clinical Features in a Population-based Sample of Subjects Aged 30 to 70 Yr. Am J Respir Crit Care Med 2001;163:685-9.

9. Karachaliou F, Kostikas K, Pastaka C, Bagiatis V, Gourgoulianis KI. Prevalence of sleep-related symptoms in a primary care population - their relation to asthma and COPD. Prim Care Resp J 2007;16:222-8. http://dx.doi.org/ 10.3132/pcrj.2007.00045

10. Murray SA, Kendall M, Boyd K, Sheikh A. Illness trajectories and palliative care. BMJ 2005;330:1007-11. http://dx.doi.org/10.1136/bmj.330.7498.1007

11. Holgate ST. Priorities for respiratory research in the UK. Thorax 2007;62:5-7. http://dx.doi.org/10.1136/thx.2006.073882

12. Fletcher $\mathrm{C}$, Peto R. The natural history of chronic airflow obstruction. BMJ 1977;1:1645-8. http://dx.doi.org/10.1136/bmj.1.6077.1645

13. Mannino DM, Watt G, Hole D, et al. The natural history of chronic obstructive pulmonary disease. Eur Respir J 2006;27:627-43. http://dx.doi.org/10.1183/09031936.06.00024605

14. Kerstjens HA, Rijcken B, Schouten JP, Postma DS. Decline of FEV1 by age and smoking status: facts, figures, and fallacies. Thorax 1997;52:820-7. 
http://dx.doi.org/10.1136/thx.52.9.820

15. Kohansal R, Martinez-Camblor P, Agustí A, Buist AS, Mannino DM, Soriano JB. The natural history of chronic airflow obstruction revisited: an analysis of the Framingham offspring cohort. Am J Respir Crit Care Med 2009;180:3-10. http://dx.doi.org/10.1164/rccm.200901-00470C

16. Stradling JR, Davies RJO. Obstructive sleep apnoea/hypopnoea syndrome: definitions, epidemiology, and natural history. Thorax 2004;59:73-8. http://dx.doi.org/10.1136/thx.2003.007161

17. The Framingham Heart Study. http://www.framingham.com/heart/. 24-1-2008. Ref Type: Electronic Citation

18. Kannel WB, Feinleib M, McNamara PM, Garrison RJ, Castelli WP. An investigation of coronary heart disease in families. The Framingham offspring study. Am J Epidemiol 1979;110:281-90.

19. van Durme YM, Verhamme KM, Stijnen $T$, et al. Prevalence, incidence, and lifetime risk for the development of COPD in the elderly: the Rotterdam study. Chest 2009;135:368-77. http://dx.doi.org/10.1378/chest.08-0684

20. Rijcken B, Schouten JP, Weiss ST, Speizer FE, van der Lende R. The relationship of nonspecific bronchial responsiveness to respiratory symptoms in a random population sample. Am Rev Respir Dis 1987;136:62-8.

21. Lundback B, Nystrom L, Rosenhall L, Stjernberg N. Obstructive lung disease in northern Sweden: respiratory symptoms assessed in a postal survey. Eur Respir J 1991;4:257-66.

22. The Copenhagen City Heart Study. Osterbroundersogelsen. A book of tables with data from the first examination (1976-78) and a five year follow-up (198183). The Copenhagen City Heart Study Group. Scand J Soc Med Suppl 1989;41:1-160.

23. Manolio TA, Weinmann GG, Buist AS, Furberg CD, Pinsky JL, Hurd SH. Pulmonary function testing in population-based studies. Am J Respir Crit Care
Med 1997;156(3 Pt 1):1004-10.

24. Kohansal R, Soriano JB, Agusti A. Investigating the natural history of lung function: facts, pitfalls, and opportunities. Chest 2009;135:1330-41. http://dx.doi.org/10.1378/chest.08-1750

25. Johns MW. A new method for measuring daytime sleepiness: the Epworth sleepiness scale. Sleep 1991;14:540-5.

26. Miller MR, Hankinson J, Brusasco V, et al. ATS/ERS Task Force. Standardisation of spirometry. Eur Respir J 2005;26:319-38. http://dx.doi.org/ 10.1183/09031936.05.00034805

27. Rabe KF, Hurd S, Anzueto A, et al. Global Strategy for the Diagnosis, Management, and Prevention of Chronic Obstructive Pulmonary Disease: GOLD Executive Summary. Am J Respir Crit Care Med 2007;176:532-55. http://dx.doi.org/10.1164/rccm.200703-456sO

28. Bellamy D, Bouchard J, Henrichsen S, et al. International Primary Care Respiratory Group (IPCRG) Guidelines: Management of Chronic Obstructive Pulmonary Disease (COPD). Prim Care Resp J 2006;15:48-65. http://dx.doi.org/10.1016/j.pcrj.2005.11.003

29. Duncan DF. (1988). Epidemiology: Basis for Disease Prevention and Health Promotion. New York: MacMillan.

30. Morris JN. (1975). Uses of Epidemiology. New York: Churchill \& Livingstone.

31. Levy ML, Quanjer PH, Booker R, Cooper BG, Holmes S, Small I. Diagnostic spirometry in primary care: Proposed standards for general practice compliant with American Thoracic Society and European Respiratory Society recommendations: a General Practice Airways Group (GPIAG) document, in association with the Association for Respiratory Technology \& Physiology (ARTP) and Education for Health. Prim Care Resp J 2009;18:130-47. http://dx.doi.org/10.4104/pcrj.2009.00054

\section{Available online at http://www.theprj.org}

